\title{
ASSOCIATING CHARACTERIZATION BENTONITE-BASED BUFFER/ BACKFILL MATERIALS BY DISTRIBUTION RATIO AND PLASTIC INDEX (PI)
}

Yi-Lin Jan

Associate Professor, Department of Civil Engineering, Ching Yun University, Jungli, Taiwan 320, R.O.C., yljan@cyu.edu.tw

Shih-Chin Tsai

Naclear Science and Technology Development Center, National Tsing Hua University, Hsinchu, Taiwan 300, R.O.C.

Chun-Nan Hsu

Professor, Department of Nuclear Science, National Tsing Hua University, Hsinchu, Taiwan 300, R.O.C.

Follow this and additional works at: https://jmstt.ntou.edu.tw/journal

Part of the Civil and Environmental Engineering Commons

\section{Recommended Citation}

Jan, Yi-Lin; Tsai, Shih-Chin; and Hsu, Chun-Nan (2007) "ASSOCIATING CHARACTERIZATION BENTONITE-BASED BUFFER/BACKFILL MATERIALS BY DISTRIBUTION RATIO AND PLASTIC INDEX (PI)," Journal of Marine Science and Technology: Vol. 15: Iss. 1, Article 3.

DOI: $10.51400 / 2709-6998.2028$

Available at: https://jmstt.ntou.edu.tw/journal/vol15/iss1/3

This Research Article is brought to you for free and open access by Journal of Marine Science and Technology. It has been accepted for inclusion in Journal of Marine Science and Technology by an authorized editor of Journal of Marine Science and Technology. 
ASSOCIATING CHARACTERIZATION BENTONITE-BASED BUFFER/BACKFILL MATERIALS BY DISTRIBUTION RATIO AND PLASTIC INDEX (PI)

\section{Acknowledgements}

The authors would like to thank the National Science Council of Taiwan, Republic of China, for financially supporting this research under Contract No. NSC_91-2626-E-231-002. 


\title{
ASSOCIATING CHARACTERIZATION OF BENTONITE-BASED BUFFER/BACKFILL MATERIALS BY DISTRIBUTION RATIO $\left(R_{d}\right)$ AND PLASTIC INDEX (PI)
}

\author{
Yi-Lin Jan*, Shih-Chin Tsai**, Chun-Nan Hsu***
}

Key words: Plastic index $(P I)$, distribution coefficient $\left(R_{d}\right)$, buffer material, additivity, seawater, groundwater.

\section{ABSTRACT}

Choosing buffer materials with the required engineering and sorption characteristics for radwaste disposal is very important. This work investigates the relationships between engineering characteristics (plastic index; $P I$ ) and sorption properties (distribution ratio; $R_{d}$ ) for two mixed buffer materials that are composed of bentonite/quartz sand and bentonite/laterite, to provide an overall functional evaluation of buffer materials. Se is the nuclide of interest, and both synthetic groundwater $(\mathrm{GW})$ and seawater $(\mathrm{SW})$ were employed in batch sorption experiments. Deionized water (DIW) was used in engineering property tests. SW and GW were also used to evaluate the effects on $P I$. The results indicate that $P I$ was proportional to the bentonite content of the tested buffer materials, independently of the solution used. The coagulation and flocculation effects lead to the ordering $P I_{\mathrm{DIW}}>P I_{\mathrm{GW}}>P I_{S W}$. The sorption of Se increased with the bentonite content in bentonite/quartz sand mixtures, and the sorption fraction increased with the laterite content in bentonite/laterite mixtures. These findings demonstrate that the sorption of Se on soil follows the order, laterite soil > bentonite > quartz sand, regardless of whether GW or SW was used. Hence, adding laterite to the mixture improved the sorption of the anionic form of Se. A mixed material with a $P I$ value of approximately 50 to 70 in GW and SW effectively balances the engineering needs with the desired chemical properties. A bentonite content of $50 \%$ and the addition of both laterite and quartz sand may be optimal for buffer materials, and is thus worthy of further study. This work further indicates that the $P I$ values of both mixtures followed the additivity rule in SW and GW, but not in DIW. The $R_{d} \mathrm{~S}$ value of Se indicated the good additivity of the bentonite/laterite mixtures in both SW and GW and of the bentonite/quartz sand mixtures in SW, but not of the bentonite/quartz sand mixtures in

Paper Submitted 03/03/06, Accepted 05/12/06. Author for Correspondence: Yi-Lin Jan.E-mail: yljan@cyu.edu.tw.

*Associate Professor, Department of Civil Engineering, Ching Yun University, Jungli, Taiwan 320, R.O.C.

**Naclear Science and Technology Development Center, National Tsing Hua University, Hsinchu, Taiwan 300, R.O.C.

***Professor, Department of Nuclear Science, National Tsing Hua University, Hsinchu, Taiwan 300, R.O.C.
GW. These results provide useful information on the choice of the composition of the buffer material, and for use in the evaluation of the overall $R_{d}$ and $P I$ of the mixture from the $R_{d}$ and $P I$ of each buffer component.

\section{INTRODUCTION}

Buffer materials for high-level radwaste disposal must exhibit particular engineering (hydraulic conductivity, thermal conductivity, mechanics, swelling and other properties) and chemical (sorption, diffusion, migration transport, and others) characteristics [10,23]. Recent studies of buffer materials focused on physical properties $[2,13,19]$; others focused on chemical properties [3, 14, 22], and a few addressed both engineering and sorption properties [9]. Learning about both the engineering and the sorption properties of potential buffer-backfill materials, mixed with various soil materials, is important.

Bentonite clay and quartz sand have been selected as potential buffer and backfill materials [11]. Bentonite is associated with a high cation exchange capacity, a high swelling potential and a low hydraulic conductivity, while quartz sand is associated with high thermal conductivity and strong mechanical properties. However, radioactive anionic species in the buffer materials mentioned above are not expected to exhibit high sorption capacity. Accordingly, composite materials that have a high capacity for absorbing both radioactive cation and anionic species in groundwater must be developed.

Some investigations have pointed out that the sorption characteristics, $R_{d}$ values, of the radionuclides $(\mathrm{RN})$ with respect to particular mineral components of the mixtures can be used to evaluate the $R_{d}$ values of the mixtures, providing additional benefits in choosing effective composite materials $[8,15]$. Many studies on the additivity sorption behavior of radionuclides on mixtures have been conducted. Some studies have demonstrated that actinides such as $\mathrm{Np}$ and Am exhibit 
quite similar additivity, but the $R_{d}$ values of Cs and $\mathrm{Sr}$ on mixtures tend to be overestimated [15]. The additivity rule for the sorption of Eu on red earth, bentonite and alumina mixtures is not generally applicable [6]. Furthermore, sorption of Se and Cs exhibited a good additivity on goethite, smectite and calcite mixtures, but Am did not [8]. Other studies for the additivity behavior of nuclides on different compositions of minerals focused on soil and their components $[16,17,18]$. Recently, the additivity rule and its applicability to soil were analyzed [21]. They pointed out that the additivity rule was formally valid based on the following assumptions; (a) sorption reaction is reversible and independent; (b) sorption reaction is in equilibrium; (c) surfaces are homogeneous; (d) ion exchangers or sorbents are insoluble; (e) no new phase is formed, and (f) no interactions occur among individual minerals of the mixture. Mixed buffer materials and complex solutions, such as seawater, are a few concerns in the cited studies.

A distribution ratio, $R_{d}$, was used to characterize materials to retard the transport of nuclides. If sorption is a surface process, then a proportional relationship must exist between sorption sites and RN. Additionally the $R_{d}$ of a mixture can be written as

$$
R_{d}(\mathrm{~mL} / \mathrm{g})=\Sigma\left(m_{i} / M\right) \times R_{d i}
$$

where $m_{i}$ is the mass of mineral $i$ in the mixture; M is the total mass of the mixture, and $R_{d i}$ is the distribution ratio of $\mathrm{RN}$ on mineral $i$.

Plastic index $(P I)$ values are typically applied to classify soil and evaluate various engineering properties such as compressive and swelling characteristics [4]. Plastic index $(P I)$ was calculated by the Atterberg liquid limit $(L L)$ and also by the plastic limit $(P L)$ of soil as follows:

$$
P I=L L-P L
$$

However, investigation on the additivity of the plastic index of mixtures will be contributive to predict the engineering properties of mixtures.

Laterite, a progressively weathered soil, exhibited better anion sorption capability as the aluminum and iron oxide content increased [5,12]. Various mass ratios of bentonite/quartz sand and bentonite/laterite mixtures were selected in this work as potential buffer materials. Batch experiments were conducted to measure the $R_{d}$ values of ${ }^{75} \mathrm{Se}$ on mixtures. Atterberg limit tests were conducted to measure $L L$ and $P L$, to evaluate $P I$ and analyze its additivity, yielding information about the elementary engineering properties of mixtures. Synthetic seawater ( $\mathrm{SW}$ ) and groundwater (GW) were used as the liquid phases to simulate the possible conditions that may be encountered during geologic disposal in an island. This study aimed primarily at establishing the relationship between sorption and the engineering properties in composite materials should, however, be beneficial in selecting an optimal composite material mixture. Additionally, the additivity of PI and $K_{d}$ can also be considered to improve the performance assessment of mixed buffer/backfill materials.

\section{MATERIALS AND METHODS}

\section{Liquid phase}

The solutions used in the batch sorption tests were synthetic compositions of GW and SW (Table 1) in which a trace amount of ${ }^{75} \mathrm{Se}$ added (Table 3 ), to simulate the possible geochemical conditions of a deep geological repository. Deionized water (DIW) was used as the solution in the Atterberg limit test to simulate the conditions for the in-situ buffer materials during the construction phase. GW and SW were also used to evaluate the effects on $P I$ as they intrude into buffer/ backfill materials.

\section{Solid phase}

The solid phase material used for both the Atterberg limit tests and the batch sorption tests were composed of varying proportions of bentonite/quartz sand and bentonite/laterite mixtures. The composite ratios of bentonite to quartz sand and bentonite to laterite used for the Atterberg limit tests were as follows; 10:0, 9:1, 7:3, 5: $5,3: 7,1: 9$ and $0: 10$ (by dry weight). The ratios of bentonite to quartz sand and bentonite to laterite in the

Table 1. The compositions of groundwater $(\mathrm{GW})$ and seawater $(\mathbf{S W})$

\begin{tabular}{lrr}
\hline Compositions & \multicolumn{1}{c}{$\mathrm{GW}$} & \multicolumn{1}{c}{$\mathrm{SW}$} \\
\hline $\mathrm{CaCl}_{2} \cdot 2 \mathrm{H}_{2} \mathrm{O}[\mathrm{g}]$ & 138.6634 & 30.3008 \\
$\mathrm{MgCl}_{2} \cdot 6 \mathrm{H}_{2} \mathrm{O}[\mathrm{g}]$ & 7.0260 & 215.8030 \\
$\mathrm{Na}_{2} \mathrm{SO}_{4}[\mathrm{~g}]$ & 16.5704 & 79.8975 \\
$\mathrm{NaHCO}_{3}[\mathrm{~g}]$ & 0.2756 & --- \\
$\mathrm{KCl}[\mathrm{g}]$ & 0.3086 & 15.2157 \\
$\mathrm{NaBr}[\mathrm{g}]$ & 1.0311 & 1.7267 \\
$\mathrm{SrCl}_{2} \cdot 6 \mathrm{H}_{2} \mathrm{O}[\mathrm{g}]$ & 2.1330 & 0.4639 \\
$\mathrm{LiCl}[\mathrm{g}]$ & 0.1221 & 0.0212 \\
$\mathrm{NaF}[\mathrm{g}]$ & 0.0672 & 0.0571 \\
$\mathrm{NaCl}[\mathrm{g}]$ & 92.2581 & 482.2667 \\
$\mathrm{H} \mathrm{BO}_{3}[\mathrm{~g}]$ & --- & 0.5145 \\
$\mathrm{Total} \mathrm{solution} \mathrm{volume} \mathrm{[L]}$ & 20 & 20 \\
\hline $\mathrm{pH}$ & $\sim 7.5$ & $\sim 7.02$ \\
\hline
\end{tabular}


Table 2. The characteristics of solid phase

\begin{tabular}{llcc}
\hline Characteristics & Bentonite & Laterite & Quartz sand \\
\hline Particle size $(\mathrm{mm})$ & $<0.074$ & $<0.074$ & $0.297 \sim 0.84$ \\
Specific area $\left(\mathrm{m}^{2} / \mathrm{g}\right)$ & 27.96 & 32.25 & 1.98 \\
$\mathrm{CEC}(\mathrm{meq} / 100 \mathrm{~g})$ & 68.5 & 14.3 & 2.62 \\
Specific gravity & 2.75 & 2.57 & Quartz \\
Major minerals & Quartz & $\mathrm{Muartz}$ hemattite & $\mathrm{Kaolinite}_{2}$, goethite \\
Major chemical & $\mathrm{MiO}_{2}(60.53 \%)$ & $\mathrm{SiO}_{2}(63.82 \%)$ & $\mathrm{SiO}_{2}(99.5 \%)$ \\
composition & $\mathrm{Al}_{2} \mathrm{O}_{3}(20.12 \%)$ & $\mathrm{Fe}_{2} \mathrm{O}_{3}(10.9 \%)$ & \\
& $\mathrm{Fe}_{2} \mathrm{O}_{3}(3.14 \%)$ & & \\
& $\mathrm{MgO}(2.65)$ & & \\
& $\mathrm{Na}_{2} \mathrm{O}(2.13 \%)$ & & \\
\hline
\end{tabular}

Table 3. pH values of GW and SW in Se sorption on mixtures

\begin{tabular}{|c|c|c|c|c|c|c|c|c|}
\hline \multirow{2}{*}{ Mixture } & \multirow{2}{*}{ Solution } & \multirow{2}{*}{$\begin{array}{l}\text { Radioactivity } \\
(\mathrm{Bq} / \mathrm{mL})\end{array}$} & \multirow{2}{*}{$\begin{array}{c}\text { Initial } \\
\mathrm{pH}\end{array}$} & \multicolumn{5}{|c|}{ Mixed Ratio } \\
\hline & & & & $10 / 0$ & $7 / 3^{3}$ & $5 / 5$ & $3 / 7$ & $0 / 10$ \\
\hline \multirow{2}{*}{$\mathrm{B} / \mathrm{Q}^{1}$} & GW & $15,537 \pm 145$ & 6.65 & 7.75 & 7.67 & 7.65 & 7.56 & 7.19 \\
\hline & SW & $12,776 \pm 227$ & 6.66 & 7.68 & 7.73 & 7.65 & 7.65 & 7.1 \\
\hline \multirow{2}{*}{$\mathrm{B} / \mathrm{L}^{2}$} & GW & $15,537 \pm 145$ & 6.53 & 7.75 & 7.16 & 7.08 & 6.71 & 6.11 \\
\hline & SW & $12,776 \pm 227$ & 6.51 & 7.68 & 7.35 & 7.17 & 7.11 & 6.05 \\
\hline
\end{tabular}

Note: 1. Bentonite mix with quartz sand.

2. Bentonite mix with laterite.

3. $7 / 3$ means bentonite $70 \%$ mixed with quartz $30 \%$ by dry weight.

batch sorption tests were 10:0, 7:3, 5:5, 3:7 and 0:10.

The laterite, progressively weathered soils, was taken from $3 \mathrm{~m}$ to $4 \mathrm{~m}$ below the surface in the Jungli area of northern Taiwan. The laterite soil sample was airdried and ground to pass through a $0.074 \mathrm{~mm}$ sieve, and then heated for 3 hours by $800^{\circ} \mathrm{C} \pm 50^{\circ} \mathrm{C}$ for removing organic matter. The MX-80 bentonite and quartz sand were commercial products. Table 2 lists the characteristics of MX-80 bentonite, laterite and quartz sand. Specific area was analyzed using $\mathrm{N}_{2}$-BET (Mircromeritics ASAP 2000), the sodium acetate method was used to determine cation exchange capacity, and $\mathrm{XRD}(\mathrm{CuK} \alpha$ radiation, MAC Sci., model MXP-18) and ICP-MS were used to identify the major elemental constituents in the solid phase.

\section{Batch sorption tests}

Batch sorption tests were conducted using a solid/ liquid ratio of $1 \mathrm{~g} / 30 \mathrm{~mL}$. The liquid-phase solutions ( $\mathrm{SW}$ and GW) were individually added to the solid phase materials with various composition ratios; they were placed in the centrifugal tubes in triplicate and shaken at $120 \mathrm{rpm}$. Samples were collected on the $14^{\text {th }}$ day following centrifugalization at $10380 \mathrm{~g}$, and the residual radioactivity of $75 \mathrm{Se}$ in the liquid phase was measured using an $\mathrm{NaI}(\mathrm{Tl}) \gamma$ counter. The $\mathrm{pH}$ values were measured using a glass electrode. The distribution ratio $\left(R_{d}\right)$ of $\mathrm{RN}$ can be calculated from the following formulae;

$$
R_{d}(m L / g)=\frac{S}{C}
$$

where $S$ is the concentration of RN sorbed on the solid phase $(\mathrm{Bq} / \mathrm{g})$, and $\mathrm{C}$ is the concentration of $\mathrm{RN}$ in solution $(\mathrm{Bq} / \mathrm{mL})$.

\section{Atterberg limit tests}

The Atterberg liquid limit test and the plastic limit test were performed on the solid-phase mixtures described above, using DIW, SW and GW. These tests were performed following the method of ASTM D4318, [1] and the $P I$ value was calculated using Eq. 2.

\section{RESULTS AND DISCUSSION}

\section{Sorption of Se on Mixtures}

Table 3 lists the $\mathrm{pH}$ values after 14 days of batch sorption reactions. The buffer capacity of bentonite 
caused the samples with bentonite contents from $30 \%$ to $100 \%$ to have $\mathrm{pH}$ values of between 7 and 8 . The laterite is an acidic soil [7] with a $\mathrm{pH}$ of as low as approximately 6 in both SW and GW.

Figures 1 and 2 indicate that the sorption increased with the bentonite content in the bentonite/quartz sand mixtures. Additionally, the sorption fraction increased with the laterite content in the bentonite/laterite mixtures. The evidence suggests: that the sorption of Se on soils followed the order laterite soil > bentonite > quartz, independently of whether GW or SW was used, perhaps because the $\mathrm{Se}\left(\mathrm{SeO}_{3}{ }^{2-}\right.$ and $\mathrm{HSeO}_{3}{ }^{-}$in aerobic aqueous solution) was sorbed primarily on the mineral surface by inner-complexation and outer-complexation; thus, the early sorption of cations on the surface of the soil is followed by an increase in positive charge, which increases the attraction for $\mathrm{SeO}_{3}{ }^{2-}$ and $\mathrm{HSeO}_{3}{ }^{-}$. The specific surface area of laterite exceeded that of bentonite (Table 2) might lead to the sorption results. The ionic radius $(1.84 \AA$ ) of Se does not allow it to replace the smaller ion in the lattice but to be sorbed only on the edges of clay minerals, the surface of oxides or the surface of hydroxides. On the other hand, the lower $\mathrm{pH}$ value the higher sorption of Se might lead to the higher sorption on laterite soil [20]. The pHs of the mixed bentonite/laterite solutions, especially that in only laterite soil, is lower than those of mixed bentonite/ quartz sand solutions. Hence, adding laterite to the mixture could promot the sorption of the anionic form of Se and slightly decrease the $\mathrm{pH}$ buffer capacity.

\section{Plastic Index of Mixtures}

DIW was used to simulate the liquid phase under construction; while SW and GW were used to simulate the intrusion of water after the construction had been completed. These three solutions were independently used to determine the liquid limit and the plastic limit for bentonite/quartz sand and bentonite/laterite mixtures, and the $P I$ values were calculated. The $P I$ values, regardless of using the three liquid phases, were proportional to the bentonite content (Figures 3 and 4). As Das [4] pointed out, the high swelling potentials were responsible for high $P I$ values of over 35 . A higher $P I$ value corresponds to lower water permeability. The experimental results demonstrated that the $P I$ values for GW were lower than those for DIW, and those for SW were lower than those for GW $\left(P I_{D I W}>P I_{G W}>P I_{S W}\right)$ in individual soil and bentonite/quartz sand mixtures. In bentonite/laterite mixtures, the $P I$ values for GW and $\mathrm{SW}$ were lower than those for DIW. For all the mixtures, the $P I$ increased significantly with the bentonite content. The bentonite content strongly affected the $P I$ value. The relatively high cation concentrations in GW and

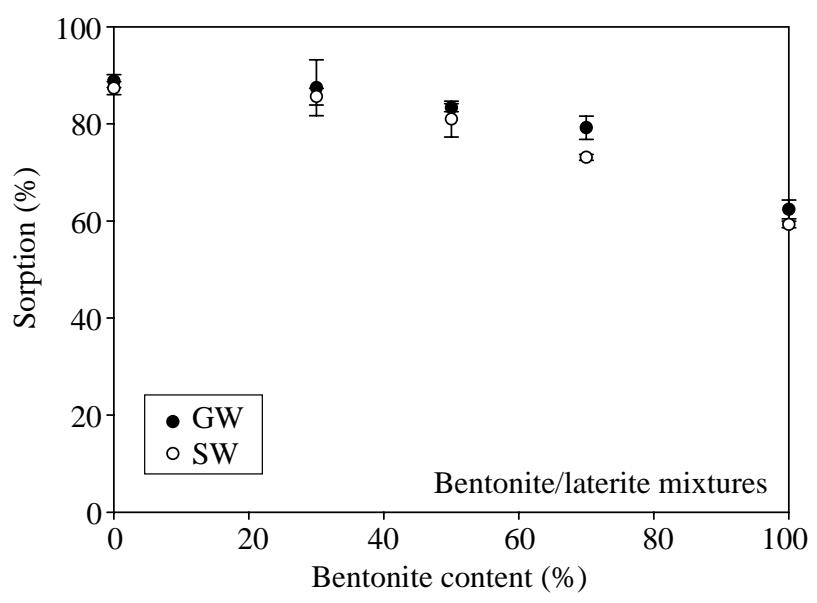

Fig. 1. Sorption percentage of Se in relation to bentonite content on bentonite/laterite mixtures.

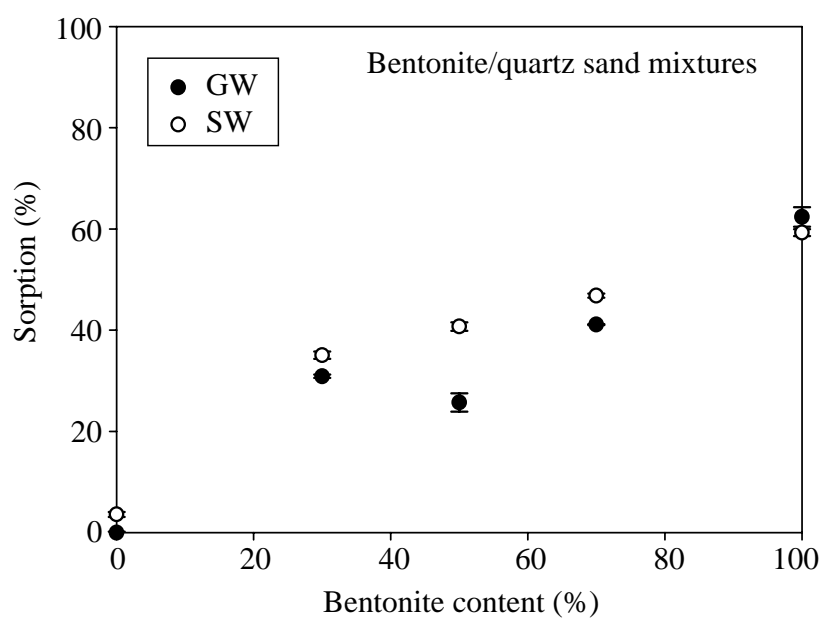

Fig. 2. Sorption percentage of Se in relation to bentonite content on bentonite/quartz sand mixtures.

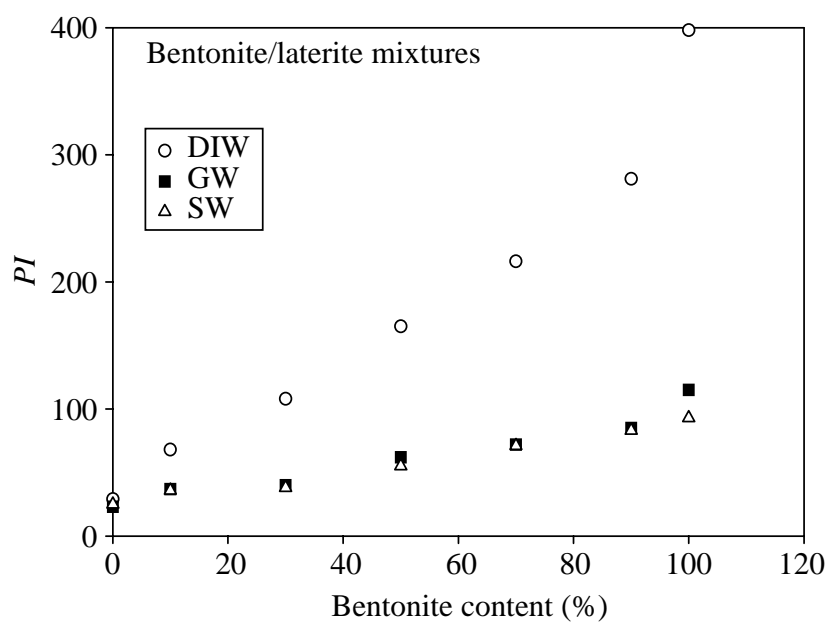

Fig. 3. Plastic index $(P I)$ in relation to bentonite content on bentonite /laterite mixtures. 
$\mathrm{SW}$, and the coagulation and flocculation that might be caused by them probably were responsible for the compression for surface electrical double layer of the bentonite particle. This fact also reveals that the swelling potential decreased when GW or SW was used, and water permeability increased. However, neither GW nor SW significantly affected the $P I$ values of quartz sand $(P I=0)$ and laterite $(P I=20$ to 30$)$.

\section{Relationship between $P I$ and $R_{d}$}

The sorption measurements described in section 3.1 can be used to evaluate the sorption characteristics of mixtures. Likewise, the PI measurements made using SW and GW, and provided in section 3.2, can be used to evaluate the engineering properties such as water permeability, swelling potential and compression properties, among others. Therefore, establishing the relationship between $R_{d}$ and $P I$ provides an advantage in choosing and evaluating the possible compositions of mixture materials. Figures 5 and 6 plot the relationships between $R_{d}$ s of Se and the PI values of mixtures in SW and GW, respectively. Figure 5 demonstrates that the Rd values decreased linearly as PI increased in both GW and $\mathrm{SW}$, on bentonite/laterite mixtures. Figure 6 showed the opposite trend: the $R_{d}$ values varied linearly with $P I$ in both GW and $\mathrm{SW}$ on bentonite/quartz sand mixtures. The results indicate that adding either quartz sand or laterite to bentonite reduced PI (decreasing the swelling force and the difficulty of construction and compressibility, but increasing the permeability). Adding quartz sand might improve the mechanical and thermal conductivities of mixtures, but it reduces the capacity to absorb Se. Adding only laterite increased the sorption of Se. Consequently, a material with a PI of approximately 50 to 70 is preferred for balancing the engineering needs against desirable chemical properties. A bentonite content of $50 \%$ and the addition of both laterite and quartz sand may be optimal for buffer materials.

\section{Additivity of $P I$ and $R_{d}$}

The following equation was used to analyze the additivity of $P I$ from as a weighted average among the various soils;

$$
P I(\text { overall })=\Sigma\left(m_{i} / M\right) \times P I_{i}
$$

where $m_{i}$ is the mass of soil $i$ in the mixture; $\mathrm{M}$ is the total mass of the mixture, and $P I_{i}$ is the plastic index of soil $i$.

The physical parameter, $P I$, is generally highly consistent with the additivity. Figures 7 and 8 indicate

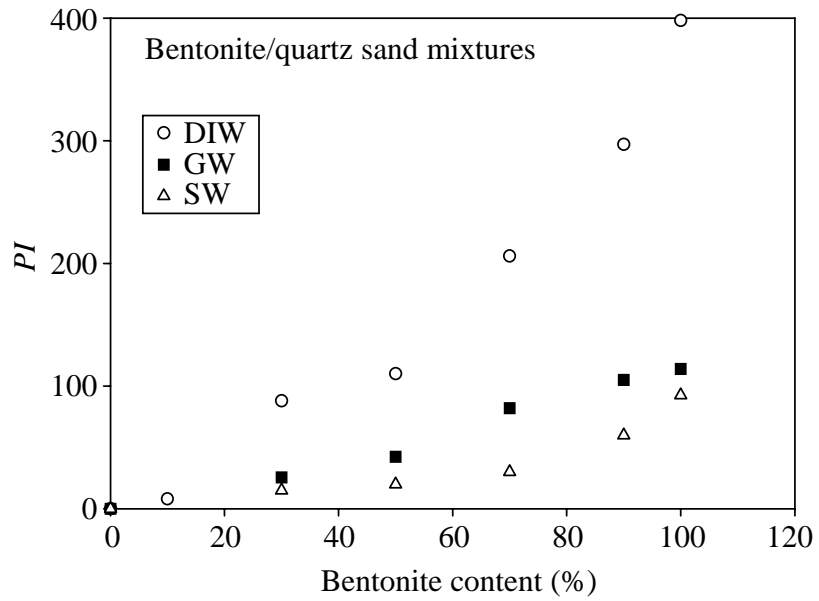

Fig. 4. Plastic index $(P I)$ in relation to bentonite content on bentonite/ quartz sand mixtures.

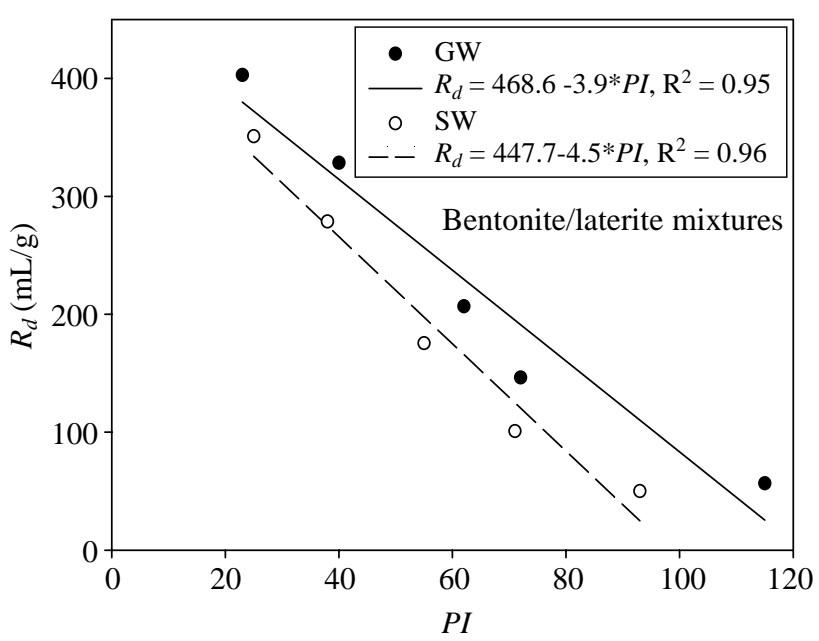

Fig. 5. Relation of $R_{d}$ of Se and $P I$ on bentonite/laterite mixtures.

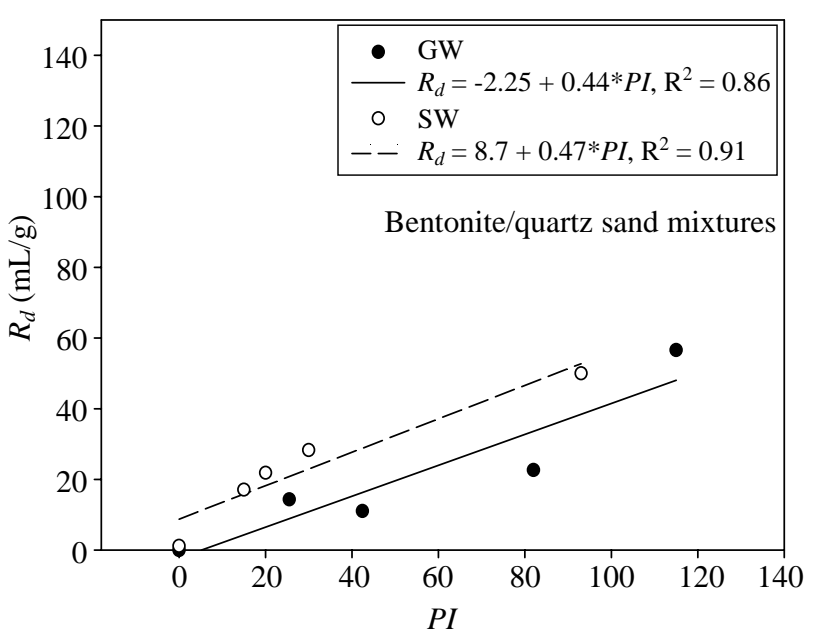

Fig. 6. Relation of $R_{d}$ of Se and $P I$ on bentonite/quartz sand mixtures. 


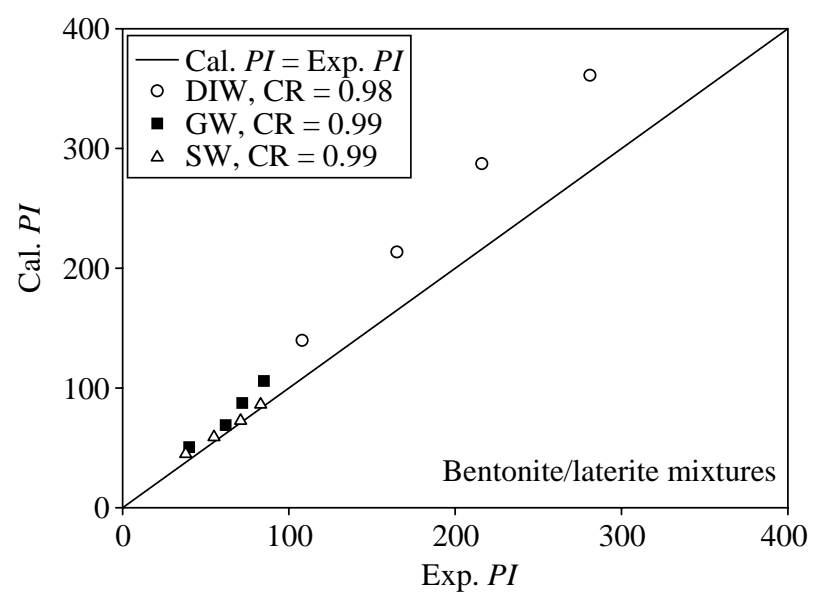

Fig. 7. Additivity of PI on bentonite/laterite mixtures (CR: correlation).

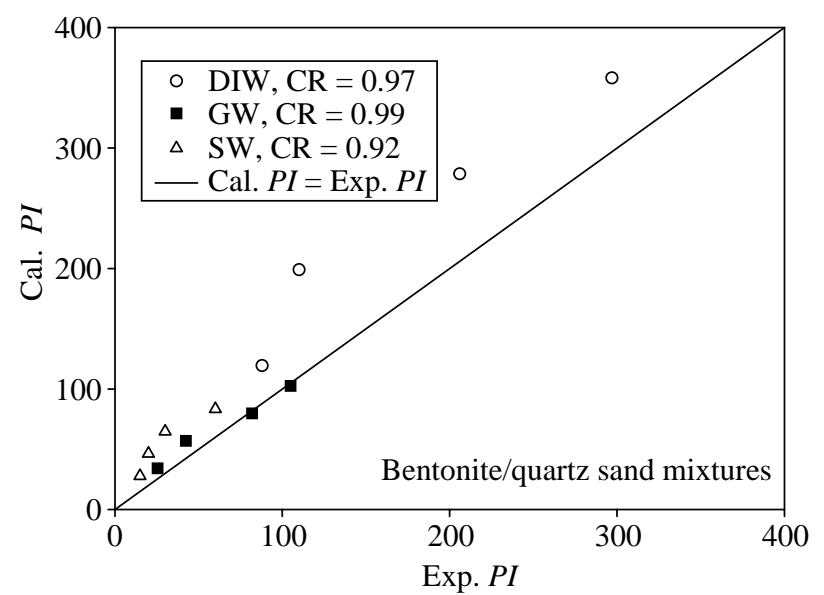

Fig. 8. Additivity of $P I$ on bentonite/quartz sand mixtures (CR: correlation).

that the PI values for the bentonite/laterite and bentonite/quartz mixtures followed the additivity rule in $\mathrm{SW}$ and GW but not in DIW. The results may have followed from the fact that the PI of bentonite in DIW greatly exceeded those of the mixtures, in which neither coagulation nor flocculation occurred.

Another issue was whether the $R_{d}$ value at various composition ratios could be predicted from the $R_{d}$ value of the individual materials could. Such prediction is useful in evaluating and choosing buffer-backfill materials. Figures 9 and 10 compare the experimental and calculated $R_{d} \mathrm{~s}$ (Eq.1) for Se in GW and SW, for the various tested mixtures. The results of this investigation showed that the $R_{d}$ value of Se exhibited good additivity for the bentonite/laterite mixtures in both SW and GW and for bentonite/quartz sand mixtures in SW, whereas similar results were not obtained for bentonite/ quartz sand mixtures in GW. Not only did the calculated and experimental $R_{d}$ values of Se for bentonite/quartz

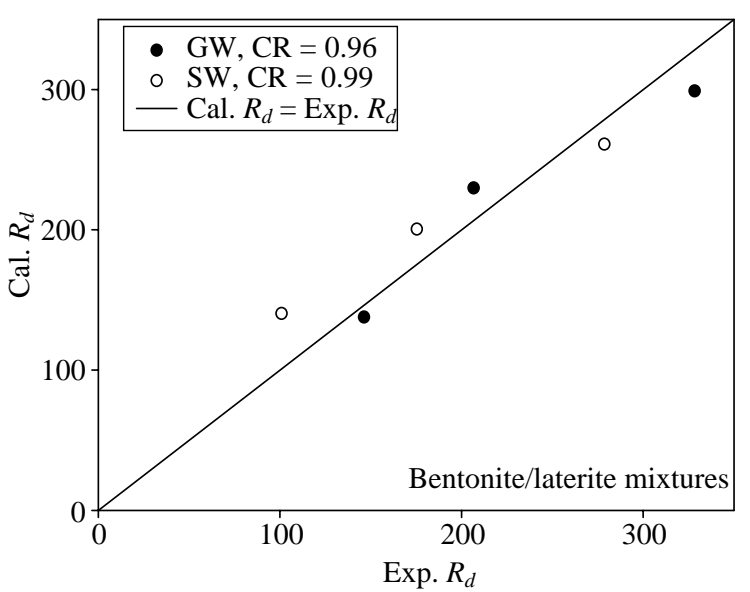

Fig. 9. Additivity of $R_{d}$ on bentonite/laterite mixtures (CR: correlation).

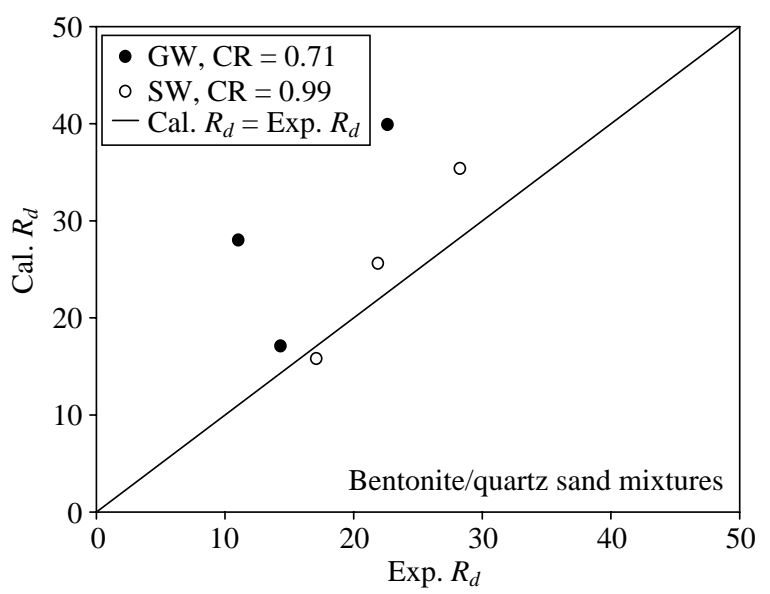

Fig. 10. Additivity of $R_{d}$ on bentonite/quartz sand mixtures (CR: correlation).

sand mixtures in GW not show high additivity, but also, they did not tend to be conservative.

\section{CONCLUSION}

Under the experimental conditions herein, the sorption percentage increased with the bentonite content in bentonite/quartz sand mixtures. Additionally, the sorption percentage increased with the laterite content in bentonite/laterite mixtures. The evidence indicated that the sorption of Se by soils followed the order laterite soil > bentonite > quartz, regardless of whether GW or SW was used. Hence, adding laterite to the mixture promoted the sorption of the anionic form of Se. PI was proportional to the bentonite content of the tested buffer material that included bentonite/quartz sand and bentonite/laterite, independently of the solution used (SW, $\mathrm{GW}$, or DIW). The results also indicated $P I_{D I W}>P I_{G W}$ $>P I_{S W}$, because of coagulation and flocculation effects. 
A material with a $P I$ of approximately 50 to 70 (in GW and $\mathrm{SW}$ ) is preferred to balance engineering needs with desired chemical properties. A bentonite content of $50 \%$ and the addition of both laterite and quartz sand may be optimal for buffer materials and should be studied further. This work further indicates that the PI values of both mixtures followed the additivity rule in $\mathrm{SW}$ and GW, but not in DIW. The $R_{d}$ value of Se exhibited good additivity on the bentonite/laterite mixtures in both SW and GW and on bentonite/quartz sand mixtures in SW, but similar results were not obtained on bentonite/quartz sand mixtures in GW. These results provide useful information concerning the choice of buffer material composition, and for evaluating the overall $R_{d}$ and PI of the mixture, from the $R_{d}$ and $P I$ of its components.

\section{ACKNOWLEDGEMENT}

The authors would like to thank the National Science Council of Taiwan, Republic of China, for financially supporting this research under Contract No. NSC_91-2626-E-231-002.

\section{REFERENCES}

1. ASTM, Annual Book of ASTM Standard: Soil and Rock, Construction, Vol. 04.08, ASTM, Philadephia, PA (1994).

2. Borgesson, L., Chijimatsu, M., Fujita, T., Nguyen, T.S., Rutqvist, J., and Jing, L., "T-H-M Characterization of a Bentonite-Based Buffer Materials by Laboratory Tests and Numerical Back Analysis," International Journal of Rock Mechanics and Mining Sciences, Vol. 38, pp. 95-104, (2001).

3. Bout, K.A., Cowper, M.M., Heath, T.G., Sato, H., Shibutani, T., and Yui, M., "Toward an Understanding of the Sorption of U(VI) and Se(IV) on Sodium Bentonite," Journal of Contaminant Hydrology, Vol. 35, pp. 141-150 (1998).

4. Das, B.M., Principles of Geotechnical Engineering, PWS-Kent Publishing Company, Boston, MA (1990).

5. Dixon, J.B. and Weed, S.B., Minerals in Soil Environments, Soil Science Society of American, Madison, WI (1989).

6. Dong, W., Wang, X., Bian, X., Wang, A., Du, J., and Tao, Z., "Comparative Study on Sorption/Desorption of Radioeuropium on Alumina, Bentonite and Red Earth: Effects of pH, Ionic Strength, and Iron Oxides in Red Earth," Applied Radiation and Isotopes, Vol. 54, pp. 603-610 (2001).

7. Hakimi, S. Syed., "Improved Iodine-125 Removal in Anionic form of Iodate by Column Method Using Laterite Soil," Journal of Radioanalytical and Nuclear Chemistry, Vol. 214, No. 2, pp. 117-131 (1996).
8. Jacquier, P., Meier, P., and Ly, J., "Asorption of Radioelements on Mixtures of Minerals-Experimental Study," Applied Geochemistry, Vol. 16, pp. 85-93 (2001).

9. Jan, Y.L., Tsai, S.C., Cheng, H.P., and Hsu, C.N., "Evaluation of Buffer Materials by Associating Engineering and Sorption Properties," Applied Radiation and Isotope, Vol. 61, pp. 1163-1172 (2004).

10. Jedinakova-Krizova, V., "Migration of Radionuclides in Environment," Journal of Radioanalytical and Nuclear Chemistry, Vol. 229, pp. 3-18 (1998).

11. JNC, "Repository Design and Engineering Technology," H12: Project to Establish the Scientific and Technical Basis for HLW Disposal in Japan, Japan Nuclear Cycle Development Institute, Japan (2000).

12. Koch-Steindl, H. and Prohl, G., "Considerations on the Behavior of Long-Lived Radionuclides in the Soil," Radiation Environment Biophysics, Vol. 40, pp. 93-104 (2001).

13. Komine, H. and Ogata, N., "Experimental Study on Swelling Characteristics of Compacted Bentonite," $\mathrm{Ca}$ nadian Geotechnology Journal., Vol. 31, pp. 478-490 (1994).

14. Muurinen, A. and Lehikoinen, J., "Porewater Chemistry in Compact Bentonite," Engineering Geology, Vol. 54, pp. 207-214 (1999).

15. NAGRA, Sorption Database for Bentonite (Technical Report 93-06), National Cooperation for the Disposal of Radioactive Waste, Switzerland (1993).

16. Ohnuki, T., "Sorption Characteristics of Strontium on Sandy Soils and their Components," Radiochimica Acta, Vol. 64, pp. 237-245 (1994).

17. Ohnuki, T., "Sorption Characteristics of Cesium on Sandy Soils and their Components," Radiochimica Acta, Vol. 65, pp. 75-80 (1994).

18. Palmer, D.A., Shiao, S.Y., Meyer, R.E., and Wethington, J., "Adsorption of Nuclides on Mixtures of Minerals," Journal of Inorganic Nuclear Chemistry, Vol. 43, pp. 3317-3322 (1981).

19. Radhakrishna, H.S. and Chan, H.T., "Thermal and Physical Properties of Candidate Buffer-Backfill Materials for Nuclear Fuel Waste Disposal Vault," Canadian Geotechnology Journal, Vol. 26, pp. 629-639 (1989).

20. Selim, H.M. and Sparks, D.L., Heavy Metals Release in Soils, Lewis Publishers, NY (2001).

21. Tao, Z. and Dong, W., "Additivity Rule and its Application to the Sorption of Radionuclides on Soils," Radiochimica Acta, Vol. 91, pp. 299-303 (2003).

22. Tsai, S.C., Ouyang, S., and Hsu, C.N., 2001. Sorption and Diffusion Behavior of $\mathrm{Cs}$ and $\mathrm{Sr}$ on Jih-Hsing Bentonite," Applied Radiation and Isotope, Vol. 54, pp. 209-215 (2001).

23. Yong, R.N., Boonsinsuk, P., and Wong, G., "Formulation of Backfill Material for a Nuclear Fuel Waste Disposal Vault," Canadian Geotechnical Journal, Vol. 23, pp. 216-228 (1996). 